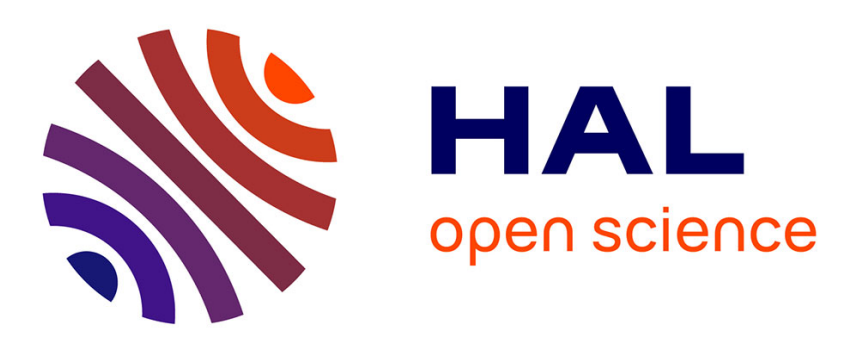

\title{
Design of Kapton based passive circuits at microwave frequencies
}

Zhening Yang, Alexandru Takacs, Samuel Charlot, Daniela Dragomirescu

\section{To cite this version:}

Zhening Yang, Alexandru Takacs, Samuel Charlot, Daniela Dragomirescu. Design of Kapton based passive circuits at microwave frequencies. European Microwave Week (EuMW), Sep 2015, Paris, France. hal-02066099

\author{
HAL Id: hal-02066099 \\ https://hal.laas.fr/hal-02066099
}

Submitted on 13 Mar 2019

HAL is a multi-disciplinary open access archive for the deposit and dissemination of scientific research documents, whether they are published or not. The documents may come from teaching and research institutions in France or abroad, or from public or private research centers.
L'archive ouverte pluridisciplinaire HAL, est destinée au dépôt et à la diffusion de documents scientifiques de niveau recherche, publiés ou non, émanant des établissements d'enseignement et de recherche français ou étrangers, des laboratoires publics ou privés. 


\section{Design of Kapton based passive circuits at microwave frequencies}

\author{
Zhening Yang \\ CNRS, LAAS, 7 avenue du colonel Roche, F-31400 \\ Toulouse, France \\ Univ de Toulouse, INSA, LAAS, F-31400 Toulouse, France \\ zyang@laas.fr \\ Samuel Charlot \\ CNRS, LAAS, 7 avenue du colonel Roche, F-31400
Toulouse, France
scharlot@laas.fr
}

\begin{abstract}
This paper presents a technology based on thin flexible polyimide substrate (Kapton) to develop passive circuits at microwave frequencies. In the first step, we characterize the Kapton polyimide (relative permittivity and loss tangent) by using a ring resonator method. Then a $60 \mathrm{GHz}$ patch antenna is designed, fabricated, and measured to validate our technology. Finally, a design of cross slot dipole antenna with a large bandwidth at $60 \mathrm{GHz}$ is proposed.
\end{abstract}

Keywords-Flexible substrate technology; Kapton RF characterization; Passive circuits.

\section{INTRODUCTION}

There is an increasing demand of high efficiency antennas and passives for applications where high frequency operation, lightweight, and conforming to a curved surface are required. Flexible electronics has spanned impressively over the past years, and flexible substrate became a strong competitor versus his rigid substrate counterparts because they are typically more rugged, lighter, portable and less expensive to manufacture [1].

TABLE I. Comparative properties of state-of-art flexible substrates [2]

\begin{tabular}{|c|c|c|c|c|c|}
\hline Material & PET & PEN & Kapton & LCP & Paper \\
\hline $\begin{array}{c}\text { Mechanical } \\
\text { properties }\end{array}$ & Good & Good & Excellent & Good & - \\
\hline $\begin{array}{c}\text { Heat } \\
\text { resistance }\end{array}$ & Low & Very good & Excellent & Good & - \\
\hline $\begin{array}{c}\text { Chemical } \\
\text { resistance }\end{array}$ & Good & Good & Good & Excellent & - \\
\hline $\begin{array}{c}\text { Electrical } \\
\text { properties }\end{array}$ & Good & Good & Good & Good & Good \\
\hline
\end{tabular}

The choice of flexible substrate for the applications at microwave frequencies is a challenge, because the substrate must exhibits good electrical (e.g. low losses) mechanical and chemical properties. Moreover, the substrate should keep these electrical properties over a wide range of frequencies and under external conditions such as temperature and pressure etc.

\author{
Alexandru Takacs \\ CNRS, LAAS, 7 avenue du colonel Roche, F-31400 \\ Toulouse, France \\ Univ de Toulouse, UPS, LAAS, F-31400 Toulouse, France \\ atakacs@laas.fr \\ Daniela Dragomirescu \\ CNRS, LAAS, 7 avenue du colonel Roche, F-31400 \\ Toulouse, France \\ Univ de Toulouse, INSA, LAAS, F-31400 Toulouse, France \\ daniela@laas.fr
}

Finally, substrates used in RF devices should be able to withstand the rigors (e.g. humidity, gasing) of its operating environment and of the fabrication processes used in its packaging [3].

Several flexible substrates used for printed circuit packaging are listed in TABLE I. One can see the characterizations for polyethylene teraphthalate (PET) [4], polyethylene naphthalate (PEN) [5], Kapton [6], liquid crystal polymers (LCP) [3] and paper-based substrate [7]. LCP has a nearly constant relative permittivity of 3.1 and low loss ( $\tan \delta=$ $0.002 \sim 0.005)$ up to millimeter wave frequency range, nearhermetic nature (water absorption $<0.04 \%$ ) makes it suitable for high frequency designs. The paper is a good candidate for its low cost, but it has limitations issues related to high frequency, absorption, and humidity. Finally, we selected Kapton as substrate for the development of our passive circuits due to its good RF and thermal properties, very good flexibility over a wide temperature range $\left(-73^{\circ} \mathrm{C}\right.$ to $\left.+400{ }^{\circ} \mathrm{C}\right)$ and its resistance to many chemical solvents.

The most widespread technologies used in microfabrication are photolithography, screen printing, and inkjet printing. (Fig.1). Inkjet printing is a direct write technology which presents a low cost advantage because the design pattern is transferred directly to the substrate and does not require masks. However, using this technology for millimeter wave applications could be a challenging task because of the highly required accuracy. Since both screen printing and inkjet printing can only offer highest resolution around $20 \mu \mathrm{m}$ [8], the traditional photolithography remains most suitable method for microfabrication at this frequency range.

This paper is organized as follows. The second chapter presents a description of the fabrication process we have developed, followed in the third chapter by a study of Kapton dielectric properties using a ring resonator method. Then, the design of a grounded coplanar waveguide feeding patch 
Traditional fabrication

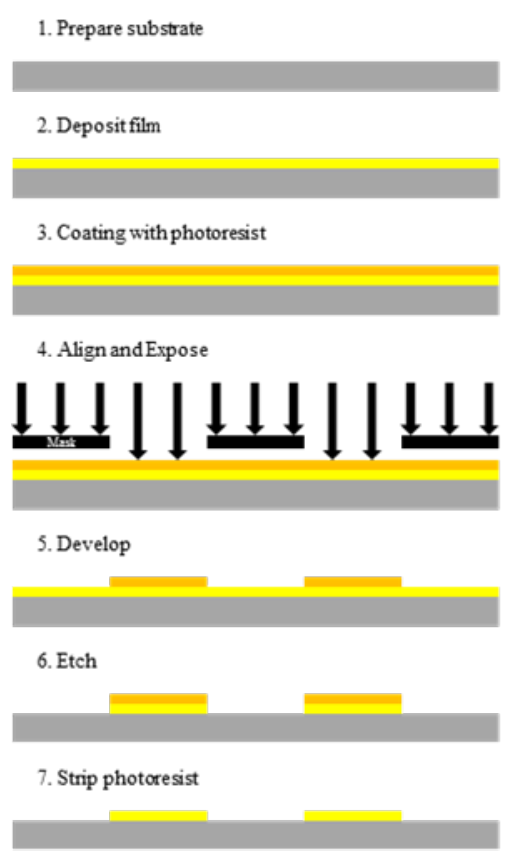

Screen printing

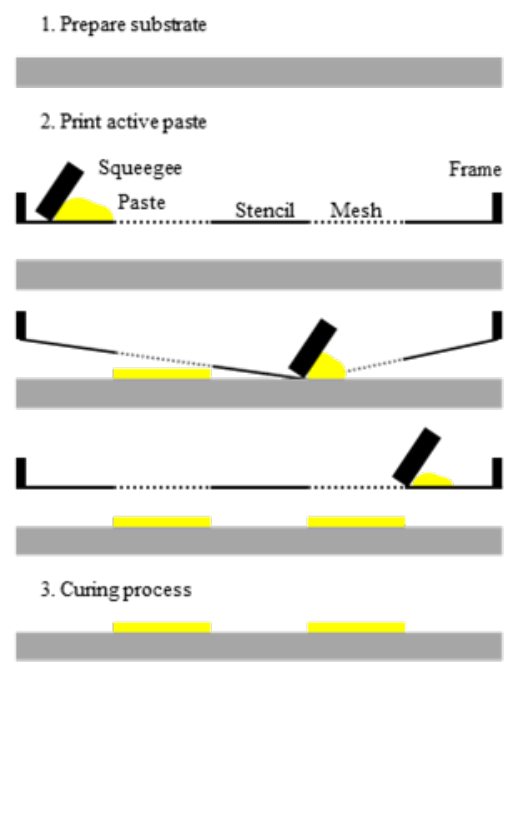

Inkjet printing

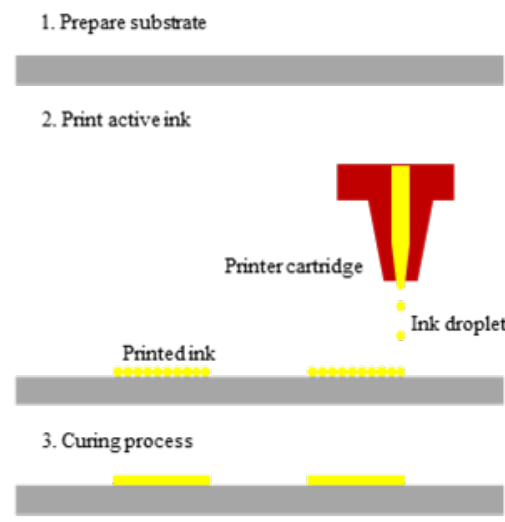

Fig. 1. Comparison of the processing steps involved in subtractive microfabrication, screen printing and inkjet printing [9].

antenna on a 127- $\mu$ m-thick Kapton in the $60 \mathrm{GHz}$ band is described. Its main features in impedance and radiation are discussed. Finally, a design of cross slot dipole antenna with a large bandwidth at $60 \mathrm{GHz}$ is proposed.

\section{TECHNOLOGICAL PROCESS FOR FLEXIBLE SUBSTRATE INTEGRATION}

To manufacture our circuits onto a flexible substrate, we have chosen the traditional photolithography, the mainly difficulty during the fabrication process lies on the flexible film handling and its use in micro-technology equipment, in order to overcome this difficulty, a 4-inch silicon wafer is used as a host carrier. One of the critical obstacles consists of finding a way to adhere the polyimide film on the Si support. This adhesion has to be compatible with the various technological stages (vacuum, solvent and temperature) and allows after manufacture a peeling without any physical or chemical constraint.

A well matured fabrication process is used to spin coating a polymer for the adhesion of the polyimide on the holding wafer. Then the Kapton polyimide is patterned on the substrates by lamination. A resin spin coating is then realized followed by a photolithography process for the metallization layer [10].

\section{RF CHARACTERIZATION OF KAPTON}

To start the design of any high-frequency structure by using numerical simulation, the knowledge of dielectric properties of the substrate becomes necessary. A commercially 127- $\mu$ m Kapton (type $500 \mathrm{HN}$ ) was chosen for our substrate, the value of thickness is in fact imposed by an effective patch antenna design in V-band. The antenna is composed by a rectangular patch on the top side of the substrate and a ground plane on the back side. Thus a minimum thickness must be respected to avoid undesired capacitive effect and to ensure a high-efficient radiation mechanism. A study of influence of thickness versus maximum antenna gain (simulation HFSS [11]) is given in Fig. 2. One can see that thicker the substrate, a better antenna gain can be obtained regardless the type of metallization.

The dielectric properties of Kapton: the relative permittivity $\varepsilon_{\mathrm{r}}$ and the loss tangent tan $\delta$ were extracted from S-parameters measurement of ring resonator, which is composed by a ring with mean radius $4.265 \mathrm{~mm}$, the width of microstrips on the Kapton surface is $306 \mu \mathrm{m}$ to make sure that the characteristic impedance of the microstrips is $50 \Omega$. There are two $80 \mu \mathrm{m}$ gaps at the end of the ring to couple the resonator to the measurement system, which provides us sufficiently coupling to measure the resonators without loading too much the test equipment.

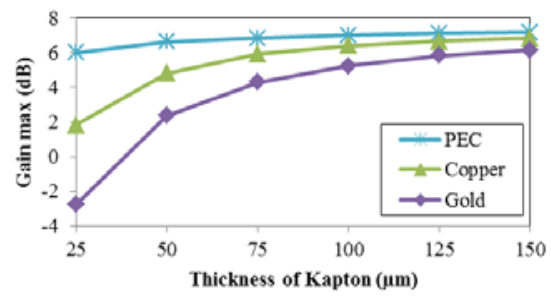

Fig. 2. Maximum antenna gain versus substrate thickness. 


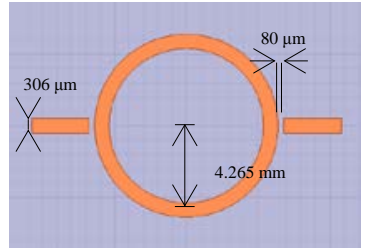

(a)

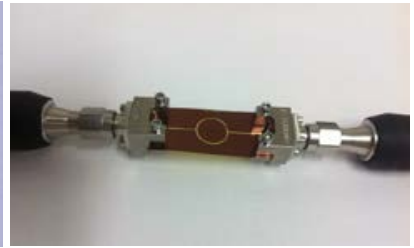

(b)
Fig. 3. (a) Ring resonator design and (b) manufactured ring resonator with two $\mathrm{K}$ "End-Launch" connectors.

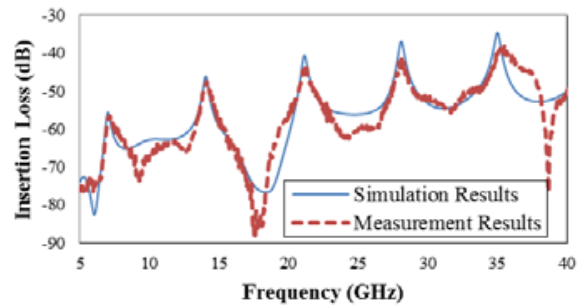

Fig. 4. Simulated and Measured Insertion Loss of the ring resonator.

\section{DESIGN AND MEASEREMENT OF KAPTON BASED PASSIVE CIRCUITS}

\section{A. Patch antenna}

A $60 \mathrm{GHz}$ grounded coplanar waveguide (GCPW) feeding rectangular patch antenna (see Fig. 5(a)) was designed, fabricated, and measured on a flexible $127-\mu$ m-thick polyimide substrate (Kapton). The GCPW-to-microstrip transition was optimized with the help of HFSS electromagnetic (EM) software in order to minimize the impedance mismatch. The antenna was then characterized in terms of return loss, gain, and radiation pattern.

The simulated and the measured return losses of the patch antenna versus frequency are presented in Fig. 6. The agreement between experiments and simulations is quite good: a relative frequency shift of only $1.4 \%$ is observed between the simulated (HFSS) and measured results. It could be due to uncertainty in the substrate permittivity value and under/over etching of the conductive patterns. The measured bandwidth, defined by return loss less than $-10 \mathrm{~dB}$, is from $62.4 \mathrm{GHz}$ to 64.4 GHz.

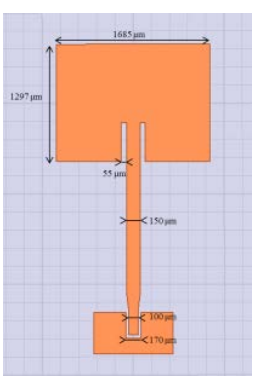

(a)

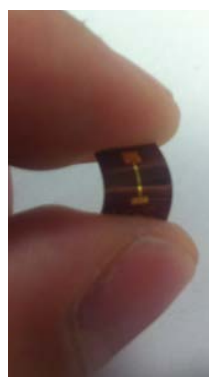

(b)

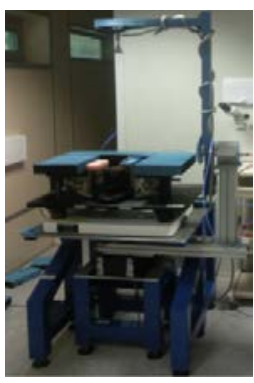

(c)
Fig. 5. (a) $60 \mathrm{GHz}$ GCPW feeding rectangular patch antenna, (b) Demonstration of the flexibility of patch antenna on Kapton., (c) Antenna radiation measurement setup.

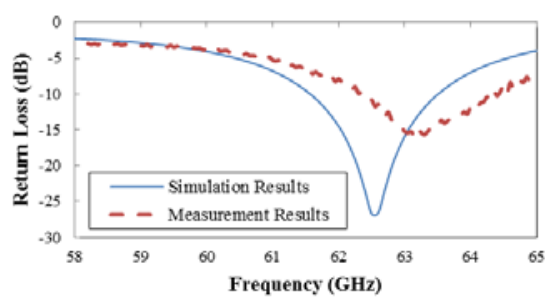

Fig. 6. Simulated and Measured Return Loss of the patch antenna.

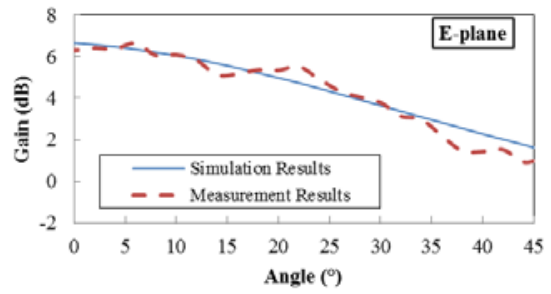

(a)

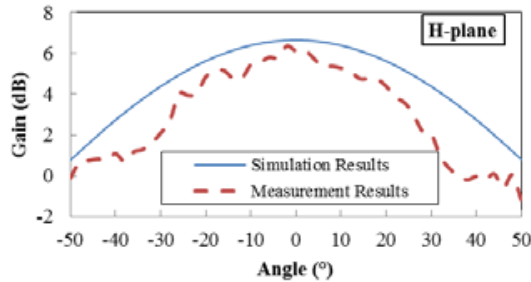

(b)

Fig. 7. (a) E-plan and (b) H-plan radiation patterns of the patch antenna at $63.2 \mathrm{GHz}$.

The far-field radiation pattern and gain were measured with a probe based antenna measurement setup at LAAS-CNRS (Fig. 5(c)). The antenna is fed through a 150- $\mu \mathrm{m}$ GroundSignal-Ground (GSG) probe, and this probe is directly connected to a $65 \mathrm{GHz}$ VNA (Anritsu 37397D) with a flexible $\mathrm{V}$-cable. Dielectric foam (Rohacell) was used on the bottom to prevent reflections from the metallic part of the setup. The antenna under test (AUT) was illumined by a field generated by a calibrated horn antenna in the $60 \mathrm{GHz}$ band with a gain around $25 \mathrm{dBi}$.

Under these conditions, a maximum gain of $6.31 \mathrm{dBi}$ was found in the perpendicular direction of the patch antenna around $63 \mathrm{GHz}$. The simulated and measured radiation patterns in the E- and H-plan are given in Fig. 7. The E-plan radiation pattern has a restricted range due to architecture of the measurement setup. Pronounced ripples are observed in the Eplane due to reflection and diffraction effects on the metallic micro-positioner and the probe. The $3-\mathrm{dB}$ beam width for the E-plan is $64^{\circ}$ and $52^{\circ}$ for the H-plan.

The results demonstrate the quality of fabrication on flexible polyimide substrate and the accuracy of measurement setup for microwave antennas implementation. 


\section{B. Cross slot dipole antenna}

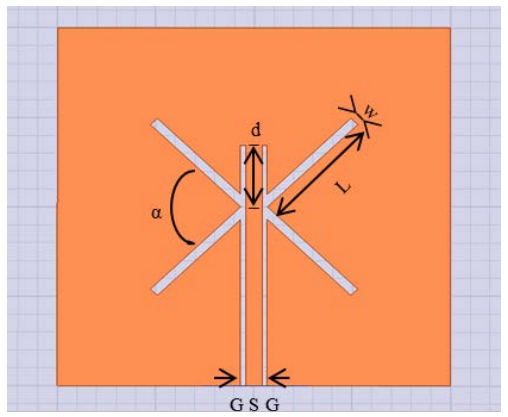

Fig. 8 . $60 \mathrm{GHz}$ CPW fed cross slot dipole antenna.

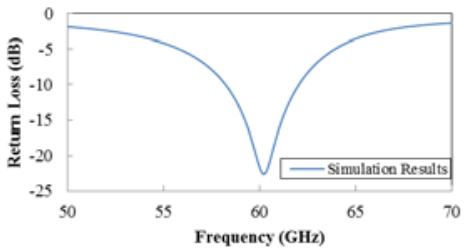

(a)

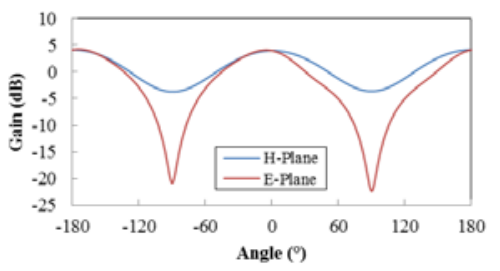

(b)

Fig. 9. (a) Simulated Return Loss of the cross slot dipole antenna and (b) radiation patterns in E-Plan and $\mathrm{H}-\mathrm{Plan}$ at $60.2 \mathrm{GHz}$.

The geometry of the proposed cross slot dipole antenna fed by a CPW is depicted in Fig. 8, the antenna is designed on a $127-\mu \mathrm{m}$ thick Kapton with a dielectric constant 3.2 and a loss tangent 0.002. $\mathrm{CPW}$ feed dimensions of $\mathrm{S}=170 \mu \mathrm{m}$ and $\mathrm{G}=$ $12 \mu \mathrm{m}$ were selected corresponding to the $50 \Omega$ GSG probe. The slot length $\mathrm{L}$ is fixed to $2.5 \mathrm{~mm}$ (quarter wavelength for 60 $\mathrm{GHz}$ ) for the simulation, the slot width $\mathrm{w}$, the stub length $\mathrm{d}$ and the angle between slots $\alpha$ were set to $40 \mu \mathrm{m}, 0.69 \mathrm{~mm}$ and $45^{\circ}$ as default respectively.

Fig. 9(a) shows the simulated return loss. The center frequency is $60.2 \mathrm{GHz}$, and the $-10 \mathrm{~dB}$ bandwidth is from 58.2 $\mathrm{GHz}$ to $62.05 \mathrm{GHz}$. The antenna radiation patterns were also presented in Fig. 9(b), a peak antenna gain of $4.02 \mathrm{~dB}$ is obtained at $60.2 \mathrm{GHz}$.

TABLE II. Study of angle $\alpha$ effect on radiation

\begin{tabular}{|c|c|c|c|c|}
\hline$\alpha\left(^{\circ}\right)$ & fc $(\mathrm{GHz})$ & Return Loss $(\mathrm{dB})$ & Maximum Gain & HPBW $\left(^{\circ}\right)$ \\
\hline 40 & 59.7 & -21.09 & 4.14 & 82 \\
\hline 45 & 60.2 & -22.76 & 4.02 & 86 \\
\hline 50 & 61.15 & -27.48 & 4.08 & 90 \\
\hline
\end{tabular}

A parametric study for the angle between slots is shown in TABLE II. It is seen that when the angle $\alpha$ increase, the peak antenna gain decrease along with a larger half power beamwitdh (HPBW) on H-plan due to the more important coupling effect when two slots approach to each other.

\section{CONCLUSION}

In this work, we demonstrate the feasibility of manufacturing microwave passive circuits at high frequency with very good RF performances through a traditional photolithography on a commercially available polyimide substrate. A quite good agreement between the measurements and simulations has been obtained. Future measurement for the cross slot dipole antenna will be carry on. This work is one step further towards a heterogeneous integration on flexible substrate of different components for wireless sensor nodes.

\section{REFERENCES}

[1] William S. Wong and Alberto Salleo. 2009. Flexible Electronics: Materials and Applications (1st ed.). Springer Publishing Company, Incorporated.

[2] « Printing Technology for Flexible Substrates », Inc. Interlingua.com (InterLingua Publishing, 2006) ISBN: 1884730469.

[3] Vyas, R.; Rida, A.; Bhattacharya, S.; Tentzeris, M. M., "Liquid Crystal Polymer (LCP): The ultimate solution for low-cost RF flexible electronics and antennas," Antennas and Propagation Society International Symposium, 2007 IEEE, vol., no., pp.1729,1732.

[4] Hettak, K.; Petosa, A.; James, R., "Flexible plastic-based inkjet printed CPW fed dipole antenna for $60 \mathrm{GHz}$ ISM applications," Antennas and Propagation Society International Symposium (APSURSI), 2014 IEEE , vol., no., pp.328,329, 6-11 July 2014.

[5] Bisognin, A.; Thielleux, J.; Wei Wei; Titz, D.; Ferrero, F.; Brachat, P.; Jacquemod, G.; Happy, H.; Luxey, C., "Inkjet Coplanar Square Monopole on Flexible Substrate for 60-GHz Applications," Antennas and Wireless Propagation Letters, IEEE , vol.13, no., pp.435, 438, 2014.

[6] http://www.dupont.com/content/dam/assets/products-andservices/membranes-films/assets/DEC-Kapton-summary-ofproperties.pdf

[7] Shaker, G.; Safavi-Naeini, Safieddin; Sangary, N.; Tentzeris, M.M. "Inkjet Printing of Ultrawideband (UWB) Antennas on Paper-Based Substrates," Antennas and Wireless Propagation Letters, IEEE , vol.10, no., pp.111,114, 2011

[8] Singh, M.; Haverinen, H.M.; Dhagat,P.; Jabbour, G.E., (2010). Inkjet printing-process and its applications. Advanced materials, 22(6), 673685

[9] Chauraya, A.; Whittow, W.G.; Vardaxoglou, J.C.; Yi Li; Torah, R.; Kai Yang; Beeby, S.; Tudor, J., "Inkjet printed dipole antennas on textiles for wearable communications," Microwaves, Antennas \& Propagation, IET , vol.7, no.9, pp.760,767, June 182013

[10] Jatlaoui, M.M.; Dragomirescu, D.; Charlot, S.; Pons, P.; Aubert, H.; Plana, R., "3D heterogeneous integration of wireless communicating nano-sensors on flexible substrate," Proc. SPIE 7821, Advanced Topics in Optoelectronics, Microelectronics, and Nanotechnologies, 2010.

[11] http://www.keysight.com/en/pc-1887116/momentum-3d-planar-emsimulator?nid=-33748.0\&cc=US\&lc=eng

[12] http://www.ansys.com/Products/Simulation+Technology/Electronics/Sig nal+Integrity/ANSYS+HFSS 